\title{
Comparative heat and gas exchange measurements in the Heidelberg Aeolotron, a large annular wind-wave tank
}

\author{
L. Nagel ${ }^{1}$, K. E. Krall ${ }^{1}$, and B. Jähne $e^{1,2}$ \\ ${ }^{1}$ Institute of Environmental Physics, University of Heidelberg, Im Neuenheimer Feld 229, 69120 Heidelberg, Germany \\ ${ }^{2}$ Heidelberg Collaboratory for Image Processing, University of Heidelberg, Speyerer Straße 6, 69115 Heidelberg, Germany \\ Correspondence to: B. Jähne (bernd.jaehne@iwr.uni-heidelberg.de)
}

Received: 13 June 2014 - Published in Ocean Sci. Discuss.: 25 June 2014

Revised: 21 November 2014 - Accepted: 17 December 2014 - Published: 26 January 2015

\begin{abstract}
A comparative study of simultaneous heat and gas exchange measurements was performed in the large annular Heidelberg Air-Sea Interaction Facility, the Aeolotron, under homogeneous water surface conditions. The use of two gas tracers, $\mathrm{N}_{2} \mathrm{O}$ and $\mathrm{C}_{2} \mathrm{HF}_{5}$, resulted not only in gas transfer velocities, but also in the measurement of the Schmidt number exponent $n$ with a precision of \pm 0.025 . The original controlled flux, or active thermographic, technique proposed by Jähne et al. (1989) was applied by heating a large patch at the water surface to measure heat transfer velocities. Heating a large patch, the active thermography technique is laterally homogeneous, and problems of lateral transport effects are avoided. Using the measured Schmidt number exponents, the ratio of the scaled heat transfer velocities to the measured gas transfer velocities is $1.046 \pm 0.040$, a good agreement within the limits of experimental uncertainties. This indicates the possibility to scale heat transfer velocities measured by active thermography to gas transfer velocities, provided that the Schmidt number exponent is known and that the heated patch is large enough to reach the thermal equilibrium.
\end{abstract}

\section{Introduction}

In 1989 Jähne et al. (1989) proposed to use heat as a proxy tracer for gas transfer velocities, then called the "controlled flux technique" (CFT). This technique provides transfer velocity measurements with high temporal resolution on the order of minutes and spatial resolution of less than a meter. However, using heat as a proxy for mass has one significant drawback. Because transfer velocities of two different tracers, including heat, scale with their diffusivity, the transfer velocity of a gas $k_{\text {gas }}$ can be extrapolated from the transfer velocity of heat $k_{\text {heat }}$ by

$k_{\text {gas }}=k_{\text {heat }}\left(\frac{D_{\text {gas }}}{D_{\text {heat }}}\right)^{n}=k_{\text {heat }}(L e)^{-n}$.

Le denotes the Lewis number. To be able to use Eq. (1) the exponent $n$ has to be known. The exponent $n$ gradually decreases from $2 / 3$ for a smooth water surface to $1 / 2$ for a wavy surface (Jähne et al., 1987b; Richter and Jähne, 2011). If the water temperature is different as well, Eq. (1) generalizes to

$k_{\text {gas }}=k_{\text {heat }}\left(\frac{S c}{P r}\right)^{-n}$,

where the Schmidt number is $S c=v / D_{\text {gas }}$ and the Prandtl number is $\operatorname{Pr}=v / D_{\text {heat }}$. In the temperature range from 0 to $40^{\circ} \mathrm{C}$, the Schmidt numbers for volatile species range from 60 to 4000 and the Prandtl number from 4.3 to 14.5 (Jähne, 2009). Diffusion of heat is approximately 100 times faster than diffusion of mass in water. By performing simultaneous gas and heat transfer measurements in the Karlsruhe linear air-sea interaction facility, Jähne et al. (1989) validated this extrapolation.

The initial radiometer used by Jähne et al. (1989) was a point-measuring device. Once thermal imaging systems with a sufficiently low noise level became available, thermographic techniques evolved into an even more useful method to investigate small-scale air-sea interaction processes. With advanced imaging devices, it was not only possible to measure transfer velocities, but also to provide a direct "insight" into the small-scale processes taking place at the ocean surface. Therefore, these imaging devices were used to study the 
mechanisms determining the transfer of mass across the airsea interface such as Langmuir circulation (Melville et al., 1998), microscale wave breaking (Jessup et al., 1997; Zappa et al., 2001, 2004), surface renewal processes (Zappa et al., 1998), and the surface velocity field (Garbe et al., 2003; Veron et al., 2008).

For field measurements, various modifications of the original CFT were applied (Haußecker et al., 2002). Haußecker et al. (1995) developed a method based on a surface renewal model to track the decay of a small heated spot and applied this technique during the Office of Naval Research (ONR) Marine Boundary Layer Accelerated Research Initiative (MBL ARI) cruise. However, this modification was not verified by independent laboratory measurements by directly comparing gas transfer and heat transfer velocities.

Schimpf et al. (1999) proposed not to apply an artificial infrared radiation to the surface, but to use the naturally occurring net heat flux instead. By an analysis of the temperature statistics, they estimated the temperature difference across the heat boundary layer at the sea surface. This approach was also based on a surface renewal model and was used in three field campaigns: CoOP 1995, CoOP1997, and GasEx1999 (Schimpf et al., 2004; Frew et al., 2004).

However, more recent experimental evidence suggests that extrapolating from heat transfer velocities to gas transfer velocities may lead to biased results. During the Fluxes, Airsea Interactions, and Remote Sensing (FAIRS) experiment, Asher et al. (2004) measured heat transfer velocities by tracking heated spots and using a surface renewal model, i.e., a Schmidt number exponent $n=1 / 2$. Simultaneously, gas transfer velocities were measured during FAIRS. Gas transfer velocities calculated by scaling the measured heat transfer velocities were found to be twice as large as the directly measured gas transfer velocities.

Atmane et al. (2004) performed simultaneous gas exchange measurements with $\mathrm{He}$ and $\mathrm{SF}_{6}$ and heat transfer measurements in a $9.1 \mathrm{~m}$ long linear wind-wave tank. They found that heat and gas transfer velocities can be well matched using a modification of the surface renewal model, the random eddy model by Harriott (1962), which assumes that the boundary layer is only partly renewed. Later Jessup et al. (2009) provided further evidence for complete and partial surface renewal. The Hariott model also leads to varying Schmidt number exponents. However, this is not the only model with this property. Jähne (1985) showed that the experimentally found variation of the Schmidt number exponent $n$ between $2 / 3$ and $1 / 2$ can be explained by different types of models, either the extended surface renewal model, where the probability for surface renewal depends on the distance to the surface, or the turbulent diffusion model with different assumptions about the increase of the turbulent diffusivity with the distance from the interface.

All previous comparisons, however, have one or both of the following two deficits. First, they were performed in linear facilities, where it is difficult to compare the locally measured heat transfer velocity with a gas transfer velocity, which is averaged over the whole facility. Second, all more recent comparisons include only the modification of active thermography with a small heated spot. With this technique, a three-dimensional modeling is actually required, because heat is also being transported horizontally by molecular diffusion, and by the shear current in the boundary layer. It is still unclear to which extend these effects influence the measured heat transfer velocity using the spot technique.

The purpose of this investigation is therefore a careful study with simultaneous heat and gas exchange measurements in a wind-wave tank with spatially more homogeneous conditions. Such a facility is the large annular Heidelberg Air-Sea Interaction Facility, the Aeolotron. The original controlled flux developed by Jähne et al. (1989) is applied, where a large patch at the water surface is heated. By heating a large patch, the active thermography technique is laterally homogeneous - provided the patch is large enough - and all problems with lateral transport effects are avoided. This investigation aims to answer the question of whether it is possible to scale heat transfer measurements performed with the CFT to gas transfer measurements without any model assumptions, provided the Schmidt number exponent $n$ is known.

\section{The wind-wave facility}

\subsection{The Heidelberg Aeolotron}

The Heidelberg Aeolotron is an annular wind-wave facility with a diameter of $8.68 \mathrm{~m}$ at the inside wall and a width of $0.61 \mathrm{~m}$ (Fig. 1). The annular shape results in a quasistationary wave field with a virtually unlimited fetch. A detailed description of the facility is given in Krall (2013, chapter 4.1) and in Jähne (2001). For the conducted measurements, deionized water with a height of $1.0 \mathrm{~m}$ was used, which corresponds to a water volume of $17.9 \mathrm{~m}^{3}$. The air part of the flume above the water has a height of $1.4 \mathrm{~m}$. Wind is generated by two axial fans mounted diametrically in the ceiling of the air space of the flume. The maximum wind speed (scaled to the reference height of $10 \mathrm{~m}$ ) that can be produced by the wind generator is $u_{10}=20 \mathrm{~m} \mathrm{~s}^{-1}$.

\subsection{Homogeneity of the wind field in the Aeolotron}

Because of the geometry of the facility, a logarithmic wind profile is not formed in the Aeolotron. Centrifugal forces due to the curved walls generate secondary currents (Schlichting, 2000). Furthermore, the wind speed is not uniformly distributed throughout the whole facility due to the positions and type of the wind generators. Bopp (2014) showed that the wind speed, and therefore also the friction velocity at the measurement location of the thermography setup, is approximately $15 \%$ higher than for the average of the whole flume. When comparing locally measured heat transfer velocities with gas transfer velocities, which are integrated over the 


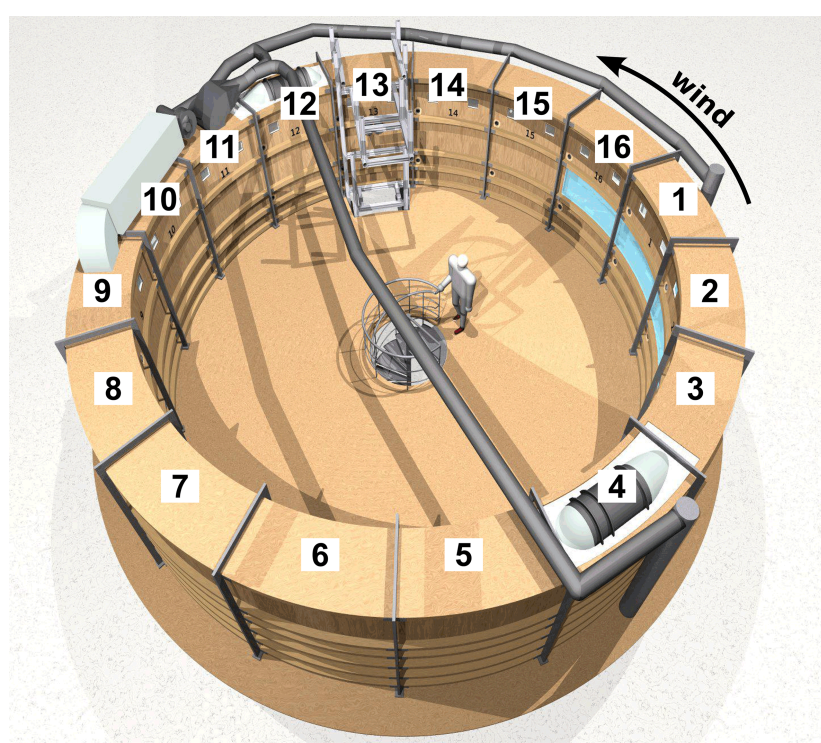

Figure 1. Rendered view of the Aeolotron, taken from Krall (2013). The 16 segments are numbered clockwise, while the wind direction is counterclockwise. The wind generating fans can be seen in segments 4 and 12 . The heat transfer velocity is measured in segment 13 , while the gas transfer measurements integrate over the whole water surface.

whole water area, this difference between the local and the averaged wind forcing has to be taken into account.

\subsection{Measurement conditions}

The measurements were conducted in spring 2010 using six different wind speed conditions between $u_{10}=2.7$ and $12.7 \mathrm{~m} \mathrm{~s}^{-1}$. Even at the highest wind speed, bubble formation by breaking waves was low. Therefore, bubble-induced gas transfer can be neglected.

Each condition was repeated two or three times. Table 1 summarizes wind speeds and friction velocities for each condition averaged over the three measurement days, as well as the mean water temperatures for each measuring day. Exact values for the wind speed and the friction velocity can be found in Appendix A for each condition. The wind speed conditions were chosen such that they were roughly equidistant in log space.

\section{The controlled flux technique}

The controlled flux technique inverts classical gas transfer measurements: a known flux density is forced to the water surface, and the resulting concentration difference is measured. For the heat exchange measurements, the setup tested in a pilot experiment under field conditions, as described in Schimpf et al. (2011), was used. A carbon dioxide laser (Evolution 100, Synrad Inc.) with an emitting wavelength of $\lambda=$ $10.6 \mu \mathrm{m}$ creates a heat flux density, which is distributed ho- mogeneously in wind direction over a rectangular area with a mirror scanning system (Micro Max 671, Cambridge Technology Inc.). The temperature response of the water surface is measured with an infrared camera (CMT256, Thermosensorik) with a resolution of $256 \times 256$ pixels in the wavelength regime of $\lambda=3.4-5 \mu \mathrm{m}$ and a noise equivalent temperature difference of less than $\Delta T=20 \mathrm{mK}$. During each condition, the laser is switched on and off with changing frequencies. This allows a system-theoretical approach for data analysis as proposed in Jähne et al. (1989). The thermal boundary layer acts like a low-pass filter to the laser forcing. For low forcing frequencies the surface reaches the equilibrium temperature of constant forcing. For higher frequencies the system can not reach the thermal equilibrium, the penetration depth is reduced, resulting in transport which is restricted to molecular diffusion and the temperature response is damped. From the measured temperature response of the system, the transfer function and therefore the cutoff frequency, which corresponds to the response time $\tau$ of the system, is determined in the Fourier domain.

From the assumption that right at the interface transport is only driven by molecular diffusion, the thickness of the mass boundary layer $z_{*}$ can be defined and can be related to the transfer velocity $k$ by

$k=\frac{D}{z_{*}}$

as derived in Jähne et al. (1989). Then, the characteristic time constant for the transport across the mass boundary layer $\tau$ is given by the ratio of the boundary layer thickness to the transfer velocity as

$\tau=\frac{z_{*}}{k}$.

Substituting Eq. (3) into Eq. (4) gives then the relation between the transfer velocity $\mathrm{k}$ and the time constant $\tau$ :

$k=\sqrt{\frac{D_{\text {heat }}}{\tau}}$.

The advantages of this data evaluation method are that it is independent of model assumption, that a flux density calibration is not required, and the low liability to reflections.

Furthermore, the temperature increase due to the periodic heating by the $\mathrm{CO}_{2}$ laser is at most a few tenths of a degree centigrade. Therefore no significant buoyancy effect is introduced, which may influence the gas transfer process and thus also the parameters $k, z_{*}$, and $\tau$.

\section{Gas exchange}

To measure gas exchange velocities $k_{\text {gas }}$, a box model method is employed. The wind-wave tank is interpreted as two well-mixed boxes. One of these boxes encompasses the 
Table 1. Measurement conditions used in this study. Shown are the mean friction velocities $u_{*}$ and the wind speeds $u_{10}$ averaged over the three measurement days, as well as the mean water temperatures for each day, $T_{\text {mean. }}$. The conditions at which measurements were conducted on each day are marked with an $\mathrm{x}$.

\begin{tabular}{cccccccc}
\hline Cond. no. & 1 & 2 & 3 & 4 & 5 & 6 & \\
$u_{*}$ averaged $\left[\mathrm{cm} \mathrm{s}^{-1}\right]$ & 0.283 & 0.370 & 0.511 & 0.707 & 1.086 & 1.713 & \\
$u_{10}$ averaged $\left[\mathrm{ms} \mathrm{s}^{-1}\right]$ & 2.74 & 3.51 & 4.69 & 6.24 & 8.90 & 12.66 & $T_{\text {mean }}\left[{ }^{\circ} \mathrm{C}\right]$ \\
\hline 26 Apr 2010 & $\mathrm{x}$ & & $\mathrm{x}$ & & $\mathrm{x}$ & & 20.1 \\
28 Apr 2010 & $\mathrm{x}$ & $\mathrm{x}$ & $\mathrm{x}$ & $\mathrm{x}$ & $\mathrm{x}$ & $\mathrm{x}$ & 20.5 \\
30 Apr 2010 & $\mathrm{x}$ & $\mathrm{x}$ & $\mathrm{x}$ & $\mathrm{x}$ & $\mathrm{x}$ & $\mathrm{x}$ & 20.8 \\
\hline
\end{tabular}

air with a volume of $V_{\mathrm{a}}$ and a homogeneous trace gas concentration of $c_{\mathrm{a}}$, and the other one the water with a volume of $V_{\mathrm{w}}$ and homogeneous tracer concentration $c_{\mathrm{w}}$. Trace gases can be exchanged between both boxes through the water surface $A$. Allowing for the possibility of air leaks with a volume flux of $\dot{V}_{\mathrm{a}}$, the transfer velocity $k_{\text {gas }}$ can be calculated using the mass balance for the air box by

$k_{\mathrm{gas}}=\frac{V_{\mathrm{a}}}{A} \cdot \frac{\dot{c}_{\mathrm{a}}+\lambda_{\mathrm{a}} c_{\mathrm{a}}}{c_{\mathrm{w}}} \cdot \frac{1}{1-\alpha c_{\mathrm{a}} / c_{\mathrm{w}}}$.

The tracer's dimensionless solubility is denoted by $\alpha$, and the leak rate is defined as $\lambda_{\mathrm{a}}=\dot{V}_{\mathrm{a}} / V_{\mathrm{a}}$. The box model Eq. (6) is only applicable in this form when the concentration of the tracer ambient air is negligible and no water leaks exist. More thorough derivations of the box model equations can be found in Kräuter (2011), Krall (2013), and Mesarchaki et al. (2014).

Measuring time-resolved air and water-side concentrations allows the measurement of the transfer velocity of a gas using Eq. (6). Additionally, the geometry of the used wind-wave tank needs to be known, as well as the solubility of the trace gas used. Also, the leak rate $\lambda_{\mathrm{a}}$ needs to be known or measured.

The instrumentation used to measure concentrations in this study as well as the determination of the leak rate and a detailed analysis of the uncertainties of gas transfer velocity are described in Mesarchaki et al. (2014) and Krall (2013). In this study, the trace gases nitrous oxide $\left(\mathrm{N}_{2} \mathrm{O}\right)$ and pentafluoroethane $\left(\mathrm{C}_{2} \mathrm{HF}_{5}\right)$ were used. Their physico-chemical parameters are listed in Table 2.

To measure the Schmidt number exponent $n$, Schmidt number scaling (see Eq. 2) is applied to two gases. The transfer velocities of two trace gases, $k_{1}$ and $k_{2}$, with differing Schmidt numbers, $S c_{1}$ and $S c_{2}$, are measured simultaneously, and the Schmidt number exponent is then calculated as

$n=-\frac{\ln \left(k_{1} / k_{2}\right)}{\ln \left(S c_{1} / S c_{2}\right)}$.
Table 2. Chemical and physical properties of the trace gases used, nitrous oxide $\left(\mathrm{N}_{2} \mathrm{O}\right)$ and pentafluoroethane $\left(\mathrm{C}_{2} \mathrm{HF}_{5}\right)$, as well as for carbon dioxide $\left(\mathrm{CO}_{2}\right)$ for comparison. All values are given at $20^{\circ} \mathrm{C}$ for freshwater. Given Schmidt numbers are calculated using $S c=$ $v / D$, with $v=0.010 \mathrm{~cm}^{2} \mathrm{~s}^{-1}$ (Kestin et al., 1978).

\begin{tabular}{lcccc}
\hline Formula & $\begin{array}{c}M \\
\mathrm{~g} \mathrm{~mol}^{-1}\end{array}$ & $\alpha$ & $\begin{array}{c}D \\
10^{-5} \mathrm{~cm}^{2} \mathrm{~s}^{-1}\end{array}$ & $S c$ \\
\hline $\mathrm{N}_{2} \mathrm{O}$ & 44.01 & $0.59^{\mathrm{a}}$ & $1.63^{\mathrm{b}}$ & 613 \\
$\mathrm{C}_{2} \mathrm{HF}_{5}$ & 120.02 & $0.45^{\mathrm{c}}$ & $0.97^{\mathrm{d}}$ & 1031 \\
$\mathrm{CO}_{2}$ & 44.01 & $0.94^{\mathrm{e}}$ & $1.67^{\mathrm{f}}$ & 599 \\
\hline
\end{tabular}

${ }^{\mathrm{a}}$ Young (1981), ${ }^{\mathrm{b}}$ Tamimi et al. (1994), ${ }^{\mathrm{c}}$ Krall (2013), ${ }^{\mathrm{d}}$ Yaws (2009),

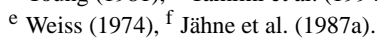

\section{Results and discussion}

\subsection{Measured heat transfer velocities}

Heat and gas transfer velocities were measured during each wind speed condition with a closed air space. The determination of the heat transfer velocities and their uncertainties is described in detail in Nagel (2014). The friction velocity was measured under the same conditions, but at a different time. The measurement of the friction velocities is described in Bopp (2014). As Bopp (2014) used slightly different wind speeds in his measurements, a polynomial of 3rd order was fitted to the almost linearly related data points of friction velocities versus wind speed measured by Bopp (2014). Here, this relationship is used to determine the averaged friction velocity for each condition. For the local heat transfer measurements, the local friction velocity is assumed to be $15 \%$ larger than the averaged one; see Sect. 2.2.

Figure 2 shows the heat transfer velocities plotted against the local friction velocity. For three conditions (no. 3 on 26 April 2010, no. 3 on 28 April 2010, and no. 1 on 30 April 2010), no transfer velocity could be determined, as the fit of the amplitude damping function did not converge due to large scatter in the measured amplitudes.

To use the system-theoretical approach, described in Sect. 3, for data analysis, it is necessary that a water parcel stays in the heated area for a time that is long enough to reach the thermal equilibrium. Therefore the response time 


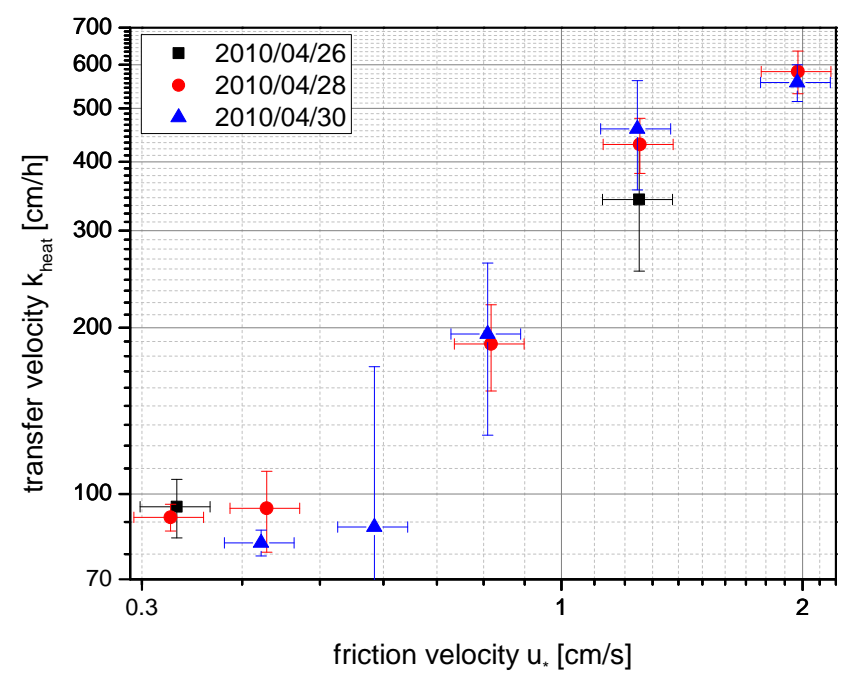

Figure 2. Measured heat transfer velocities plotted against the locally measured friction velocity. Dates are given in YYYY/MM/DD.

$\tau$ has to be smaller than the residence time of a water parcel in the heated patch. The size of the heated patch was $40 \mathrm{~cm}$ along-wind and $23 \mathrm{~cm}$ cross-wind. The required horizontal length scale can be estimated as follows. Gutsche (2014) measured the mean surface drift velocity in the Aeolotron. A good estimate is $0.036 \pm 6 \%$ of the reference wind speed: $u_{\mathrm{s}}=0.036 U_{\text {ref }}$. The horizontal length scale $x_{*}$ is then the product of the surface drift velocity $u_{\mathrm{s}}$ and the timescale $\tau$ : $x_{*}=u_{\mathrm{s}} \tau$. Taking the values from Tables A1 and A2, the horizontal length scale is only $1.7 \mathrm{~cm}$ at the highest wind speed, but at the second-highest wind speed it is already $23 \mathrm{~cm}$. For that reason it is likely that the transfer velocity of the lowest wind speed is overestimated, because the heated area was too small.

Because the expected response time of the system decreases with increasing wind speed, the used laser forcing frequencies were increased as well. Nevertheless, to determine the response time, it is necessary that the system can reach the thermal equilibrium at the lowest used forcing frequencies. How well the thermal equilibrium is reached at the lowest forcing frequencies influences the accuracy of the determination of the response time. Figures 3 and 4 show two examples of amplitude damping dependent upon the laser forcing frequency recorded under different wind speed conditions. The fit of the amplitude damping curve has a higher accuracy in Fig. 3, where the thermal equilibrium is reached at more than one of the low forcing frequencies. In contrast, the thermal equilibrium is barely reached in Fig. 4, leading to a larger uncertainty in the response time. Therefore, the accuracy of the calculated heat transfer velocities varies significantly.

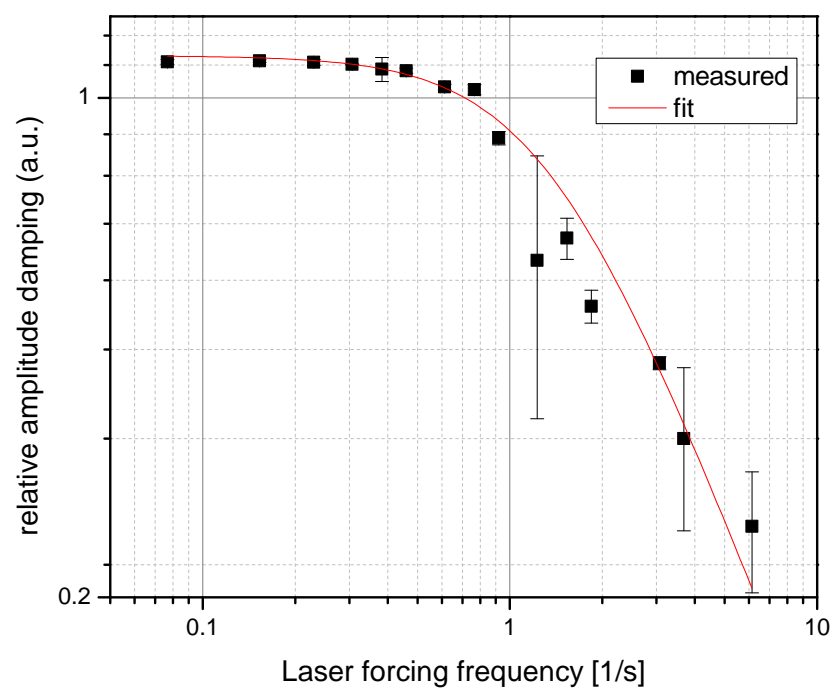

Figure 3. Example for measured amplitude damping plotted against the laser forcing frequency at a friction velocity of $u_{*}=$ $0.28 \mathrm{~cm} \mathrm{~s}^{-1}$. At low forcing frequencies the thermal equilibrium was easily reached.

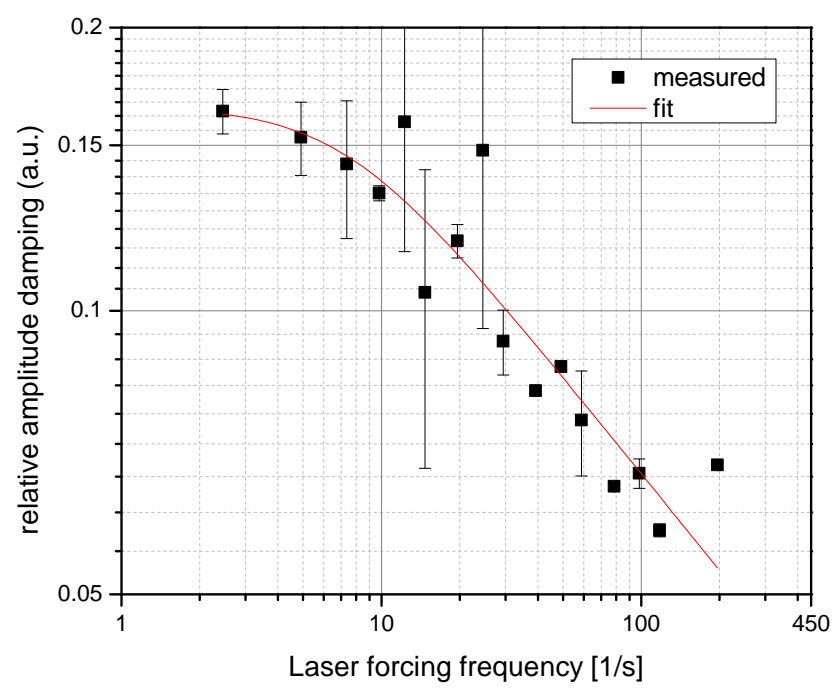

Figure 4. Example for measured amplitude damping plotted against that of the laser forcing frequency at a friction velocity of $u_{*}=$ $2.46 \mathrm{~cm} \mathrm{~s}^{-1}$. At low forcing frequencies the thermal equilibrium was barely reached.

\subsection{Gas transfer velocities and Schmidt number exponent}

The gas transfer velocities, which were measured simultaneously to the heat exchange velocities, are shown in Fig. 5 against the friction velocity averaged over the whole facility. The transfer velocity shown is scaled to a Schmidt number of $S c=600$ using Schmidt number scaling; see Eq. (2). The Schmidt number exponent $n$ used for scaling was calculated using the measured transfer velocities of both gases, 


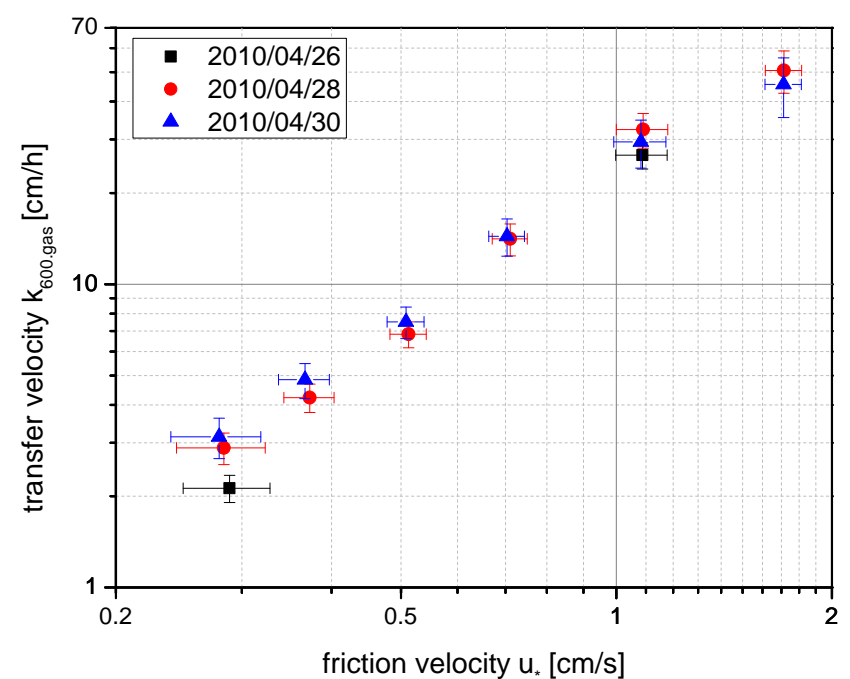

Figure 5. Measured gas transfer velocities scaled to a Schmidt number of $S c=600$ plotted against the global averaged friction velocity. Dates are given in YYYY/MM/DD.

$\mathrm{N}_{2} \mathrm{O}$ as well as $\mathrm{C}_{2} \mathrm{HF}_{5}$, using Eq. (7). Therefore, scaling the measured gas transfer velocities of both gases to $S c=600$ yields the same transfer velocity $k_{600}$. That means that, even though the transfer velocities of two gases were measured in each condition, only one transfer velocity can be shown. For condition no. 3 on 26 April 2010 (see Table 1), which was measured as the first condition on that day, no gas transfer velocity could be calculated. During this condition the trace gases were insufficiently mixed into the water, leading to spatially varying water-side concentration, making the box model which requires homogeneous concentrations (see Sect. 4) no longer applicable.

The measured Schmidt number exponent $n$ is shown in Fig. 6. It shows a smooth transition from $n=2 / 3$ for the low wind speeds to $n=1 / 2$ for the highest wind speed as described in Sect. 1. The error estimation of the Schmidt number exponent was done with a mean difference approach, resulting in an error of less than 0.025 . The measured gas transfer velocities $k_{600}$ as well as the transition of the Schmidt number exponent $n$ from $2 / 3$ to $1 / 2$ are in good agreement with previous studies in wind-wave facilities (Jähne et al., 1987b; Zappa et al., 2001; Nielsen, 2004; Krall, 2013).

\subsection{Comparison between measured gas and heat transfer velocities}

To compare heat and gas transfer, all measured transfer velocities are scaled to a Schmidt number of $S c=600$ by Schmidt number scaling, as described in Sect. 1, Eq. (2), using the measured Schmidt number exponents.

Figure 7 shows the measured transfer velocities for heat and for a gas dependent upon the friction velocity. The shown gas transfer velocities are integrated over the whole facility,

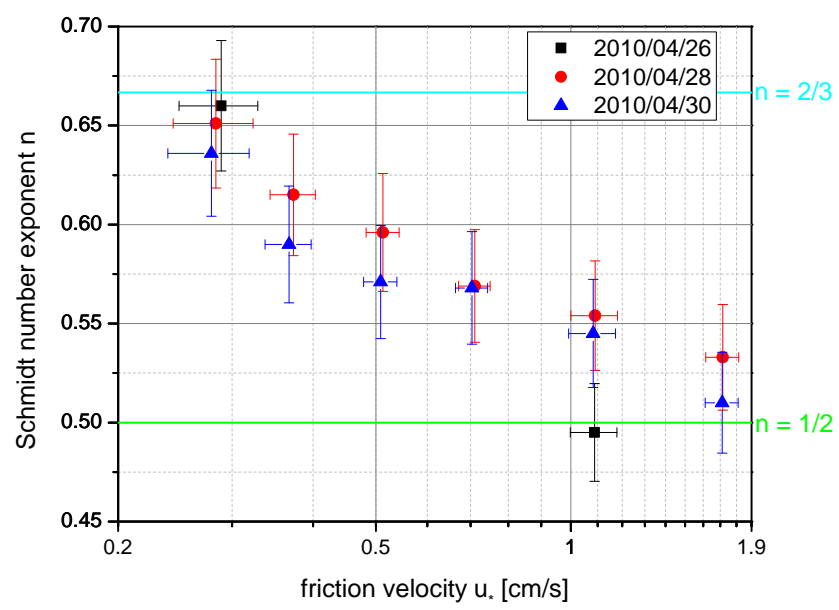

Figure 6. Measured Schmidt number exponents $n$ with an error of $5 \%$ plotted against the global averaged friction velocity $u_{*}$. Dates are given in YYYY/MM/DD.

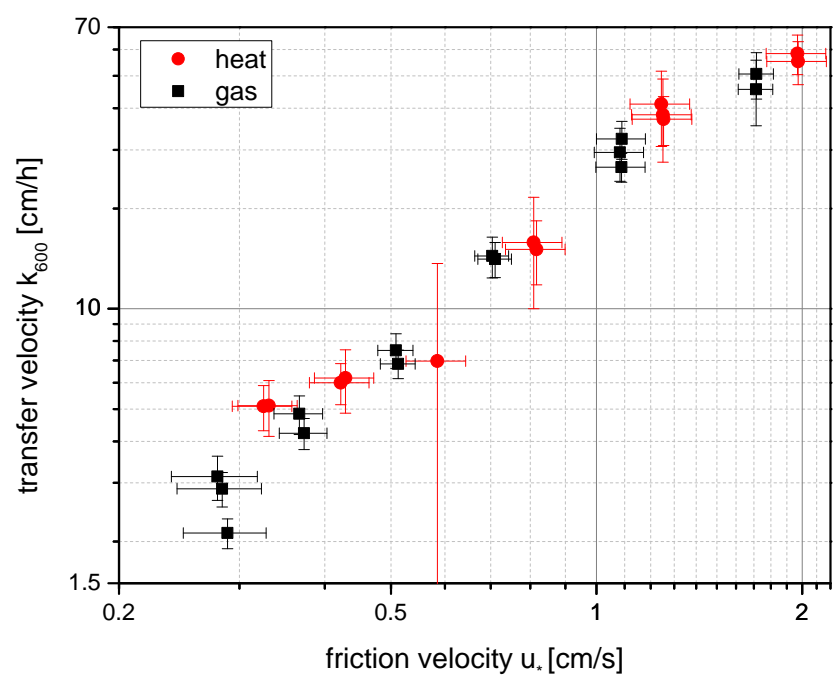

Figure 7. Simultaneously measured heat and gas transfer velocities, both scaled to a Schmidt number of $S c=600$ plotted against that of the friction velocity. The friction velocities for the local heat transfer measurements are $15 \%$ enhanced in comparison to the global values for the friciton velocities for the gas transfer velocity measurements.

while the heat transfer velocities are measured locally. As described in Sect. 2.2, the wind speed and the friction velocity in the measurement region of the local heat transfer measurements are approximately $15 \%$ higher than the averaged value of the whole facility. Therefore the transfer velocities are measured at different friction velocities, although they are measured simultaneously. The uncertainty for the local friction velocity is approximately $5 \%$, while uncertainties of the friction velocity averaged over the whole facility are taken directly from Bopp (2014). 


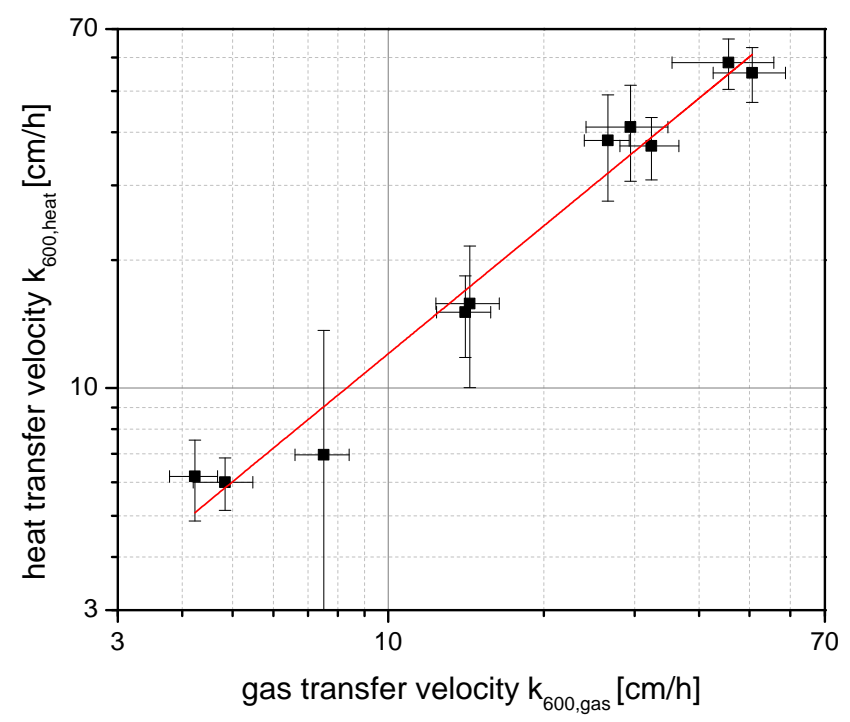

Figure 8. Heat transfer velocities plotted against simultaneously measured gas transfer velocities, both scaled to a Schmidt number of $S c=600$. The best-fit line has a slope of $1.20 \pm 0.04$.

Figure 7 shows the good agreement between the scaled heat and the scaled gas transfer velocities. To quantify the deviation of the scaled heat transfer velocities, Fig. 8 shows them against the simultaneous measured gas transfer velocities, also scaled to $S c=600$. The best-fit line shows a slope of $1.20 \pm 0.04$. That means that the heat transfer velocities are approximately $20 \%$ higher than the simultaneously measured gas transfer velocities. As discussed above, $15 \%$ can be attributed to the difference in the friction velocity of the local compared to the integrated measurements. Therefore the scaling factor between the heat transfer velocities and the values, which were expected from the gas transfer measurements, is just $1.046 \pm 0.04$. This is within the conservatively estimated error budget, which contains three different sources of errors.

First, the absolute uncertainty in the Schmidt number exponent $n$ leads to a relative uncertainty for the heat transfer velocity scaled to a gas transfer velocity of

$\frac{\sigma_{k}}{k_{\mathrm{gas}}}=\ln \left(\frac{S c}{P r}\right) \sigma_{n}$

where $\sigma_{k}$ and $\sigma_{n}$ are the absolute uncertainties for the transfer velocity and the Schmidt number exponent, respectively. For $\sigma_{n}=0.025$ (Fig. 6) and $S c / P r \approx 600 / 7.2$, the relative scaling for $k_{\mathrm{gas}}$ error is $11 \%$.

Second, the accuracy of the absolute value of the Schmidt number is less than 5\% (Jähne et al., 1987a). Third, the heat transfer velocities were measured at a local friction velocity, which is $15 \pm 5 \%$ higher than the friction velocity averaged over the whole facility. These three contributions lead, linearly added, to a total error of less than $21 \%$.

\section{Conclusions and outlook}

This study showed that it is possible to scale heat transfer velocities to gas transfer velocities. The mean deviation found experimentally is a factor of $1.046 \pm 0.04$. This is well below the possible maximum systematic deviation, conservatively estimated to be $21 \%$. This result was found by simultaneous gas transfer and heat transfer measurements using the original approach of Jähne et al. (1989), in the large annular Heidelberg Aeolotron wind wave tank. This approach does not depend on any model assumptions about the transfer processes; only the Schmidt number exponent $n$ must be known. This opens up the opportunity to apply this technique to field measurements.

However, three issues must be addressed carefully.

First, water parcels at the surface must stay in the heated patch for a time that is longer than the response time $\tau$ of the heat transfer across the boundary layer (see Sect. 5.1). This condition is much harder to meet in the field than in a wind-wave facility and requires a platform that moves with the mean water surface drift velocity.

Second, the Schmidt number exponent $n$ has to be known with a high level of certainty. All experimental and theoretical evidence suggests that it varyies between $2 / 3$ and $1 / 2$. With an unknown Schmidt number exponent in this range, the uncertainty of scaling from heat transfer to gas transfer is approximately a factor of 2 for a Schmidt number of 600 . It is even larger for higher Schmidt numbers (tracers such as $\mathrm{SF}_{6}$, DMS, and most organic volatiles) and lower for lower Schmidt numbers (e.g., He). Recent measurements by Krall (2013) showed that the exponent $n$ does not simply decrease with increasing wind speed, but it also depends on the degree of contamination of the water surface with surface active material. Thus the relation between the Schmidt number exponent $n$ and the surface conditions needs to be investigated carefully. Measurements by Zappa et al. (2004) and Jessup et al. (2009) indicate that it might be possible to infer the exponent from the infrared image sequences themselves, because it is possible to analyze microscale wave breaking and full/partial surface renewal events from them.

And third, active thermography does not see bubbleinduced gas transfer. This is a clear disadvantage for scaling to gas transfer rates for high-wind-speed conditions. However, it can be turned into a clear advantage for combined gas transfer-heat transfer field campaigns to determine the bubble-induced portion of gas transfer. 


\section{Appendix A: Measured transfer velocities}

Table A1 shows the environmental variables, and Table A2 the numerical results of the measurements described above.

Table A1. Environmental parameters at all measured conditions, including the date, the reference wind speed $u_{\text {ref }}$, the wind speed $u_{10}$, the friction velocity $u_{*}$, the water temperature $T_{\text {water }}$, the Schmidt number of $\mathrm{N}_{2} \mathrm{O}$, and the Schmidt number exponent $n$. The Prandtl number of heat was $\operatorname{Pr}=7.2$ under all measured conditions. The temperature-dependent Schmidt number of $\mathrm{N}_{2} \mathrm{O}$ was taken from Degreif (2006).

\begin{tabular}{|c|c|c|c|c|c|c|c|c|}
\hline Number & Date & $\begin{array}{r}u_{\mathrm{ref}} \\
{\left[\mathrm{ms}^{-1}\right]}\end{array}$ & $\begin{array}{r}u_{10} \\
{\left[\mathrm{~ms} \mathrm{~s}^{-1}\right]} \\
\text { averaged }\end{array}$ & $\begin{array}{r}u_{*} \\
{\left[\mathrm{cms}^{-1}\right]} \\
\text { averaged }\end{array}$ & $\begin{array}{r}u_{*} \\
{\left[\mathrm{~ms}^{-1}\right]} \\
\text { local }\end{array}$ & $\begin{array}{r}T_{\text {water }} \\
{\left[{ }^{\circ} \mathrm{C}\right]} \\
\text { averaged }\end{array}$ & $\begin{array}{r}S c \\
\mathrm{~N}_{2} \mathrm{O}\end{array}$ & $n$ \\
\hline 1 & 26 Apr 2010 & 2.05 & 2.78 & 0.288 & 0.332 & 20.1 & 597 & 0.66 \\
\hline 2 & 28 Apr 2010 & 2.02 & 2.73 & 0.283 & 0.326 & 20.4 & 586 & 0.65 \\
\hline 3 & 30 Apr 2010 & 1.99 & 2.69 & 0.279 & 0.321 & 20.8 & 575 & 0.64 \\
\hline 4 & 28 Apr 2010 & 2.66 & 3.53 & 0.373 & 0.429 & 20.5 & 585 & 0.62 \\
\hline 5 & 30 Apr 2010 & 2.61 & 3.48 & 0.367 & 0.422 & 20.8 & 572 & 0.59 \\
\hline 6 & 26 Apr 2010 & 3.64 & 4.70 & 0.512 & 0.589 & 20.1 & 598 & - \\
\hline 7 & 28 Apr 2010 & 3.64 & 4.71 & 0.513 & 0.590 & 20.5 & 585 & 0.60 \\
\hline 8 & 30 Apr 2010 & 3.61 & 4.68 & 0.509 & 0.585 & 20.9 & 573 & 0.57 \\
\hline 9 & 28 Apr 2010 & 4.87 & 6.26 & 0.711 & 0.817 & 20.5 & 584 & 0.57 \\
\hline 10 & 30 Apr 2010 & 4.83 & 6.21 & 0.704 & 0.809 & 20.9 & 573 & 0.57 \\
\hline 11 & 26 Apr 2010 & 6.55 & 8.91 & 1.088 & 1.251 & 20.1 & 597 & 0.50 \\
\hline 12 & 28 Apr 2010 & 6.56 & 8.92 & 1.089 & 1.253 & 20.5 & 584 & 0.55 \\
\hline 13 & 30 Apr 2010 & 6.53 & 8.87 & 1.082 & 1.244 & 20.9 & 573 & 0.55 \\
\hline 14 & 28 Apr 2010 & 8.34 & 12.67 & 1.715 & 1.972 & 20.5 & 584 & 0.53 \\
\hline 15 & 30 Apr 2010 & 8.33 & 12.66 & 1.712 & 1.969 & 20.9 & 573 & 0.51 \\
\hline
\end{tabular}

Table A2. Measured response times $\tau$, heat transfer velocities $k_{\text {heat }}$, transfer velocities of $\mathrm{N}_{2} \mathrm{O}\left(k_{\mathrm{N}_{2} \mathrm{O}}\right)$, and the $k_{600}$ calculated from $k_{\text {heat }}$ and $k_{\mathrm{N}_{2} \mathrm{O}}$.

\begin{tabular}{cccccc}
\hline Number & $\begin{array}{c}\tau \\
{[\mathrm{s}]}\end{array}$ & $\begin{array}{c}k_{\text {heat }} \\
{\left[\mathrm{cm} \mathrm{s}^{-1}\right]}\end{array}$ & $\begin{array}{c}k_{600} \\
{\left[\mathrm{~cm} \mathrm{~s}^{-1}\right]} \\
\text { heat }\end{array}$ & $\begin{array}{c}k_{\mathrm{N}_{2} \mathrm{O}} \\
{\left[\mathrm{cm} \mathrm{s}^{-1}\right]}\end{array}$ & $\begin{array}{c}k_{600} \\
{\left[\mathrm{~cm} \mathrm{~s}^{-1}\right]} \\
\mathrm{N}_{2} \mathrm{O}\end{array}$ \\
\hline 1 & $2.079 \pm 0.520$ & $94.74 \pm 11.51$ & $5.13 \pm 0.50$ & $2.13 \pm 0.22$ & $2.12 \pm 0.22$ \\
2 & $2.270 \pm 0.259$ & $90.67 \pm 5.03$ & $5.17 \pm 0.23$ & $2.93 \pm 0.35$ & $2.88 \pm 0.34$ \\
3 & - & - & - & $3.22 \pm 0.49$ & $3.13 \pm 0.48$ \\
\hline 4 & $2.108 \pm 0.726$ & $94.08 \pm 15.75$ & $6.29 \pm 0.97$ & $4.29 \pm 0.46$ & $4.23 \pm 0.45$ \\
5 & $2.807 \pm 0.310$ & $81.54 \pm 4.37$ & $6.16 \pm 0.30$ & $4.97 \pm 0.64$ & $4.84 \pm 0.64$ \\
\hline 6 & - & - & - & - & - \\
7 & - & - & - & $6.94 \pm 0.67$ & $6.84 \pm 0.67$ \\
8 & $2.463 \pm 4.834$ & $87.05 \pm 83.06$ & $7.15 \pm 6.79$ & $7.70 \pm 0.87$ & $7.51 \pm 0.30$ \\
\hline 9 & $0.535 \pm 0.196$ & $186.85 \pm 33.28$ & $15.32 \pm 4.19$ & $14.32 \pm 1.61$ & $14.10 \pm 1.70$ \\
10 & $0.491 \pm 0.348$ & $194.97 \pm 67.17$ & $16.22 \pm 8.87$ & $14.77 \pm 1.71$ & $14.39 \pm 2.01$ \\
\hline 11 & $0.160 \pm 0.085$ & $341.55 \pm 88.06$ & $38.34 \pm 22.62$ & $26.67 \pm 2.64$ & $26.61 \pm 2.66$ \\
12 & $0.101 \pm 0.024$ & $430.15 \pm 49.27$ & $37.66 \pm 10.79$ & $32.79 \pm 3.22$ & $32.31 \pm 4.22$ \\
13 & $0.089 \pm 0.041$ & $458.57 \pm 102.8$ & $42.20 \pm 24.80$ & $30.21 \pm 3.21$ & $29.47 \pm 5.32$ \\
\hline 14 & $0.055 \pm 0.010$ & $583.12 \pm 51.69$ & $55.99 \pm 14.81$ & $51.38 \pm 4.84$ & $50.65 \pm 8.08$ \\
15 & $0.060 \pm 0.009$ & $556.95 \pm 42.42$ & $59.75 \pm 13.39$ & $46.67 \pm 4.40$ & $45.60 \pm 10.14$ \\
\hline
\end{tabular}


Acknowledgements. We would like to thank M. Bopp for fruitful discussions concerning the friction velocity in the Aeolotron. Financial support for this work by the German Federal Ministry of Education and Research (BMBF) joint project "Surface Ocean Processes in the Anthropocene" (SOPRAN, FKZ 03F0462F, and 03F0611F) within the international SOLAS project and of the Deutsche Forschungsgemeinschaft and Ruprecht-Karls-Universität Heidelberg within the funding program Open Access Publishing is gratefully acknowledged.

Edited by: J. Shutler

\section{References}

Asher, W. E., Jessup, A. T., and Atmane, M. A.: Oceanic application of the active controlled flux technique for measuring airsea transfer velocities of heat and gases, J. Geophys. Res., 109, C08S12, doi:10.1029/2003JC001862, 2004.

Atmane, M. A., Asher, W., and Jessup, A. T.: On the use of the active infrared technique to infer heat and gas transfer velocities at the air-water free surface, J. Geophys. Res., 109, C08S14, doi:10.1029/2003JC001805, 2004

Bopp, M.: Luft- und wasserseitige Strömungsverältnisse im ringförmigen Heidelberger Wind-Wellen-Kanal (Aeolotron), Masterarbeit, Institut für Umweltphysik, Universität Heidelberg, Germany, available at: http://www.ub.uni-heidelberg.de/archiv/ 17151 (last access: 23 January 2015), 2014.

Degreif, K.: Untersuchungen zum Gasaustausch - Entwicklung und Applikation eines zeitlich aufgelösten Massenbilanzverfahrens, Dissertation, Institut für Umweltphysik, Fakultät für Physik und Astronomie, Univ. Heidelberg, available at: http://www.ub. uni-heidelberg.de/archiv/6120 (last access: 23 January 2015), 2006.

Frew, N., Bock, E., Schimpf, U., Hara, T., Haussecker, H., Edson, J., McGillis, W., Nelson, R., McKenna, S., Uz, B., and Jähne, B.: Air-sea gas transfer: Its dependence on wind stress, small-scale roughness, and surface films, J. Geophys. Res., 109, C08S17, doi:10.1029/2003JC002131, 2004.

Garbe, C. S., Spies, H., and Jähne, B.: Estimation of surface flow and net heat flux from infrared image sequences, J. Math. Imaging Vis., 19, 159-174, doi:10.1023/A:1026233919766, 2003.

Gutsche, M.: Surface Velocity Measurements at the Aeolotron by Means of Active Thermography, Masterarbeit, Institut für Umweltphysik, Universität Heidelberg, Germany, available at: http://www.ub.uni-heidelberg.de/archiv/17431 (last access: 23 January 2015), 2014.

Harriott, P.: A Random Eddy Modification of the Penetration Theory, Chem. Eng. Sci., 17, 149-154, doi:10.1016/00092509(62)80026-8, 1962.

Haußecker, H., Reinelt, S., and Jähne, B.: Heat as a proxy tracer for gas exchange measurements in the field: principles and technical realization, in: Air-Water Gas Transfer: Selected Papers from the Third International Symposium on Air-Water Gas Transfer, edited by: Jähne, B. and Monahan, E. C., 405-413, AEON, Hanau, doi:10.5281/zenodo.10401, 1995.

Haußecker, H., Schimpf, U., Garbe, C. S., and Jähne, B.: Physics from IR image sequences: Quantitative analysis of transport models and parameters of air-sea gas transfer, in: Gas Trans- fer at Water Surfaces, edited by: Saltzman, E., Donelan, M., Drennan, W., and Wanninkhof, R., Vol. 127 of Geophysical Monograph, 103-108, American Geophysical Union, doi:10.1029/GM127p0103, invited, 2002.

Jessup, A. T., Zappa, C. J., and Yeh, H. H.: Defining and quantifying microscale wave breaking with infrared imagery, J. Geophys. Res., 102, 23145-23153, 1997.

Jessup, A. T., Asher, W. E., Atmane, M., Phadnis, K., Zappa, C. J., and Loewen, M. R.: Evidence for complete and partial surface renewal at an air-water interface, Geophys. Res. Lett., 36, 1-5, doi:10.1029/2009GL038986, 2009.

Jähne, B.: Transfer processes across the free water interface, Habilitation thesis, Institut für Umweltphysik, Fakultät für Physik und Astronomie, Univ. Heidelberg, doi:10.5281/zenodo.12202, 1985.

Jähne, B.: Aeolotron: the Heidelberg air sea interaction facility, CD-ROM, Hanau: AEON Verlag und Studio, doi:10.5281/zenodo.10281, available at: https: //www.youtube.com/watch?v=UN0WLx9Ow9Q (last access: 23 January 2015), 2001.

Jähne, B.: Air-sea gas exchange, in: Encyclopedia Ocean Sciences, edited by: Steele, J. H., Turekian, K. K., and Thorpe, S. A., 147156, Elsevier, doi:10.1016/B978-012374473-9.00642-1, invited, 2009.

Jähne, B., Heinz, G., and Dietrich, W.: Measurement of the diffusion coefficients of sparingly soluble gases in water, J. Geophys Res., 92, 10767-10776, doi:10.1029/JC092iC10p10767, 1987a.

Jähne, B., Münnich, K. O., Bösinger, R., Dutzi, A., Huber, W., and Libner, P.: On the parameters influencing air-water gas exchange, J. Geophys. Res., 92, 1937-1950, doi:10.1029/JC092iC02p01937, 1987b.

Jähne, B., Libner, P., Fischer, R., Billen, T., and Plate, E. J.: Investigating the transfer process across the free aqueous boundary layer by the controlled flux method, Tellus, 41B, 177-195, doi:10.1111/j.1600-0889.1989.tb00135.x, 1989.

Kestin, J., Sokolov, M., and Wakeham, W. A.: Viscosity of Liquid Water in the Range $-8^{\circ} \mathrm{C}$ to $150{ }^{\circ} \mathrm{C}$, J. Phys. Chem. Ref. Data, 7, 941-948, doi:10.1063/1.555581, 1978.

Krall, K. E.: Laboratory Investigations of Air-Sea Gas Transfer under a Wide Range of Water Surface Conditions, Dissertation, Institut für Umweltphysik, Fakultät für Physik und Astronomie, Univ. Heidelberg, available at: http://www.ub.uni-heidelberg.de/ archiv/14392 (last access: 23 January 2015), 2013.

Kräuter, C.: Aufteilung des Transferwiderstands zwischen Luft und Wasser beim Austausch flüchtiger Substanzen mittlerer Löslichkeit zwischen Ozean und Atmosphäre, Diplomarbeit, Institut für Umweltphysik, Fakultät für Physik und Astronomie, Univ. Heidelberg, available at: http://www.ub.uni-heidelberg.de/ archiv/13010 (last access: 23 January 2015), 2011.

Melville, W. K., Shear, R., and Veron, F.: Laboratory measurements of the generation and evolution of Langmuir circulations, J. Fluid Mech., 364, 31-58, doi:10.1017/S0022112098001098, 1998.

Mesarchaki, E., Kräuter, C., Krall, K. E., Bopp, M., Helleis, F., Williams, J., and Jähne, B.: Measuring air-sea gas exchange velocities in a large scale annular wind-wave tank, Ocean Sci. Discuss., 11, 1643-1689, doi:10.5194/osd-11-1643-2014, 2014.

Nagel, L.: Active Thermography to Investigate Small-Scale AirWater Transport Processes in the Laboratory and the Field, Dissertation, Institut für Umweltphysik, Fakultät für Chemie 
und Geowissenschaften, Univ. Heidelberg, available at: http: //www.ub.uni-heidelberg.de/archiv/16831 (last access: 23 January 2015), 2014.

Nielsen, R.: Gasaustausch - Entwicklung und Ergebnis eines schnellen Massenbilanzverfahrens zur Messung der Austauschparameter, Dissertation, Institut für Umweltphysik, Fakultät für Physik und Astronomie, Univ. Heidelberg, available at: http: //www.ub.uni-heidelberg.de/archiv/5032 (last access: 23 January 2015), 2004.

Richter, K. and Jähne, B.: A laboratory study of the Schmidt number dependency of air-water gas transfer, in: Gas Transfer at Water Surfaces 2010, edited by: Komori, S., McGillis, W., and Kurose, R., 322-332, available at: http://hdl.handle.net/2433/ 156156 (last access: 23 January 2015), 2011.

Schimpf, U., Haußecker, H., and Jähne, B.: Studies of air-sea gas transfer and micro turbulence at the ocean surface using passive thermography, in: The Wind-Driven Air-Sea Interface: Electromagnetic and Acoustic Sensing, Wave Dynamics and Turbulent Fluxes, edited by: Banner, M. L., Sydney, Australia, 1999.

Schimpf, U., Garbe, C., and Jähne, B.: Investigation of transport processes across the sea surface microlayer by infrared imagery, J. Geophys. Res., 109, C08S13, doi:10.1029/2003JC001803, 2004.

Schimpf, U., Nagel, L., and Jähne, B.: The 2009 SOPRAN active thermography pilot experiment in the Baltic Sea, in: Gas Transfer at Water Surfaces 2010, edited by: Komori, S., McGillis, W., and Kurose, R., 358-367, available at: http://hdl.handle.net/ 2433/156156, 2011.

Schlichting, H.: Boundary Layer Theory, Springer, 8th Edn., 2000.
Tamimi, A., Rinker, E. B., and Sandall, O. C.: Diffusion Coefficients for Hydrogen Sulfide, Carbon Dioxide, and Nitrous Oxide in Water over the Temperature Range 293-368 K, J. Chem. Eng. Data, 39, 330-332, doi:10.1021/je00014a031, 1994.

Veron, F., Melville, W. K., and Lenain, L.: Wave-coherent air-sea heat flux, J. Phys. Oceanogr., 38, 788-802, doi:10.1175/2007JPO3682.1, 2008.

Weiss, R. F.: Carbon Dioxide in Water and Seawater: The Solubility of a Non-Ideal Gas, Mar. Chem., 2, 203-215, doi:10.1016/03044203(74)90015-2, 1974.

Yaws, C. L.: Diffusion coefficient in water - organic compounds, in: Transport Properties of Chemicals and Hydrocarbons, chap. 12, 502-593, William Andrew, doi:10.1016/B9780-8155-2039-9.50017-X, 2009.

Young, C. L. (Ed.): IUPAC Solubility Data Series: Oxides of Nitrogen, Vol. 8, Pergamon Press, Oxford, England, 1981.

Zappa, C. J., Jessup, A. T., and Yen, H.: Skin layer recovery of free-surface wakes: Relation to surface renewal and dependence on heat flux and background turbulence, J. Geophys. Res., 103, 21711-21721, doi:10.1029/98JC01942, 1998.

Zappa, C. J., Asher, W. E., and Jessup, A. T.: Microscale wave breaking and air-water gas transfer, J. Geophys. Res., 106, 93859391, doi:10.1029/2000JC000262, 2001.

Zappa, C. J., Asher, W. E., Jessup, A. T., Klinke, J., and Long, S. R.: Microbreaking and the enhancement of air-water transfer velocity, J. Geophys. Res., 109, C08S16, doi:10.1029/2003JC001897, 2004. 